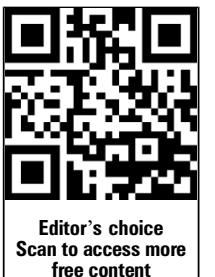

\section{- Additional material is published online only. To view please visit the journal online (http://dx.doi.org/10.1136/ thoraxjnl-2012-203123). \\ ${ }^{1}$ Nottingham Respiratory Research Unit, University of Nottingham, City Hospital, Nottingham, UK \\ ${ }^{2}$ Epidemiology and Public Health, University of Nottingham, City Hospital, Nottingham, UK \\ ${ }^{3}$ Respiratory Medicine, Nottingham University Hospitals NHS Trust, City Hospital, Nottingham, UK ${ }^{4}$ NHS Health and Social Care Information Centre, Leeds, West Yorkshire, UK}

\section{Correspondence to} Dr Helen Powell, C100, Clinical Sciences Building, Nottingham City Hospital, Hucknall Road, Nottingham NG5 1PB, UK: helen.powell@nottingham.ac.uk

Received 12 December 2012 Revised 8 April 2013 Accepted 15 April 2013 Published Online First 17 May 2013

\section{SLinked}

- http://dx.doi.org/10.1136/ thoraxjnl-2013-203536

To cite: Powell HA, Tata LJ, Baldwin DR, et al. Thorax 2013;68:826-834.

\title{
Early mortality after surgical resection for lung cancer: an analysis of the English National Lung cancer audit
}

\author{
Helen A Powell, ${ }^{1,2}$ Laila J Tata, ${ }^{2}$ David R Baldwin, ${ }^{3}$ Rosamund A Stanley, ${ }^{4}$ \\ Aamir Khakwani, ${ }^{2}$ Richard B Hubbard ${ }^{1,2}$
}

\begin{abstract}
Introduction For appropriately staged non-small cell lung cancer (NSCLC) surgical resection can dramatically improve survival, but some may not be offered this treatment because of concerns about perioperative mortality.
\end{abstract}

Methods We used data from the National Lung Cancer Audit (NLCA) to determine the proportions of English patients who died within 30 and 90 days after surgery for NSCLC. We quantified the predictors of early postoperative death and using these results devised a score to predict risk of death within 90 days of surgery.

Results We analysed data on 10991 patients operated on between 2004 and 2010. Three per cent (334) of patients died within 30 days of their procedure and $5.9 \%$ (647) within 90 days. Age was strongly associated with early postoperative death (adjusted OR within 90 days for 80-84 years vs $70-74$ years: $1.46,95 \% \mathrm{Cl} 1.07$ to 1.98); significant associations were also observed with performance status (PS) (adjusted OR within 90 days for PS 2 vs PS 0: $2.40,95 \% \mathrm{Cl} 1.68$ to 3.41), as well as lung function, stage and procedure type.

Conclusions Our results show that age is the most important predictor of death within both of these early postoperative periods. We used the data in the NLCA to develop a predictive score, based on an English population and specific to lung cancer surgery, which estimates risk of death within 90 days; this score should be tested in future cohorts.

\section{INTRODUCTION}

For appropriately staged non-small cell lung cancer (NSCLC) surgery is generally accepted as the most effective treatment, but some people may not be offered surgery because of concerns about perioperative mortality. Hospitals with higher resection rates have better overall lung cancer survival, and it has been suggested that if all National Health Service (NHS) Trusts increased their resection rates the proportion of people surviving lung cancer would improve. ${ }^{1}$

Several predictive models for early postoperative mortality have been developed, ${ }^{2-4}$ and the British Thoracic Society recommend the use of 'a global risk score such as Thoracoscore to estimate the risk of death' when assessing patients' eligibility for lung cancer surgery. ${ }^{5}$ In developing Thoracoscore, Falcoz et $a l^{6}$ included 10122 patients $57 \%$ of whom had cancer) who underwent any thoracic

\section{Key messages}

What is the key question?

- What are the mortality rates 30 and 90 days after lung cancer surgery in England, and can we use the data in the National Lung Cancer Audit (NLCA) to develop a predictive score to assist with the estimation of mortality risk within the early postoperative period?

\section{What is the bottom line?}

- Three per cent of patients in England died within 30 days of potentially curative surgery for non-small cell lung cancer between 2004 and 2010, and a further $2.9 \%$ (a total of $5.9 \%$ ) died within 90 days. There were sufficient data in the NLCA to derive a predictive score based on 90 -day mortality after lung cancer surgery.

\section{Why read on?}

- We present early mortality figures according to patient features and procedure type, demonstrate the importance of looking beyond 30-day mortality and compare our score with the commonly used Thoracoscore.

surgical procedure between 2002 and 2005. The score predicts risk of in-hospital mortality and has recognised limitations, particularly with regard to lung cancer surgery.?

Like Thoracoscore, almost all previous studies of early mortality in lung cancer surgery ${ }^{2-4} 8-10$ are based on 30-day or in-hospital mortality. These end points were used because they were felt to measure mortality directly attributable to the surgical procedure. For patients and their relatives, however, we believe an estimate of mortality within 90 days, which includes postoperative recovery time, may be more appropriate.

The National Lung Cancer Audit (NLCA) has collected demographic, tumour and treatment data from English NHS Trusts since 2004, and has been shown to be representative of people with lung cancer in England. ${ }^{11}$ We used these data to estimate the proportion of patients who died within 30 and 90 days of potentially curative surgery for NSCLC and performed a multivariate analysis to quantify risk factors for death within 30 days and within 90 days. Our final aim was to see whether we could 
use the data in the NLCA to produce a predictive score for early death after thoracic surgery which was specifically for people with lung cancer, and looked beyond 30-day mortality.

\section{METHODS}

\section{Study population}

Our initial dataset consisted of patients in the NLCA database first seen in an NHS Trust between 1 January 2004 and 31 March 2010 who had their record linked with their Hospital Episode Statistics (HES) data from 1 April 1997 to 31 March 2010.

\section{Definition of surgery}

Within this dataset we identified patients who had an Office of Population Censuses and Surveys Classification of Interventions (OPCS-4) code for a thoracic surgical procedure likely to have been performed with curative intent for NSCLC; these codes are recorded in the HES database (code list in online supplementary appendix A). We included procedures which took place between 1 January 2004 and 31 March 2010. We excluded patients with stage IIIB or IV disease and those with International Classification of Diseases-revision 10 (ICD-10) codes for metastases recorded prior to the procedure date.

We categorised procedures as pneumonectomy, bi-lobectomy, lobectomy, segmentectomy/wedge resection or other. When more than one relevant procedure code was identified for an individual, the most extensive procedure was used; for the few patients who had codes for more than one procedure of the same type, we used the date of the most recent procedure. If recorded procedure dates differed between HES and the NLCA we calculated the difference between the dates: if this was more than 10 days the patient was excluded from further analysis. We also excluded patients with a procedure date more than 3 months before or 6 months after their lung cancer diagnosis so that patient features, which are usually recorded at the time of diagnosis, might still be representative of the state of the patient at the time of surgery.

\section{Definition of outcome}

All records in the NLCA are linked to Office of National Statistics data to obtain dates of death. For patients in this study death records were last updated in August 2011 (16 months after the last procedure date). We used these dates, and HES procedure dates, to calculate the proportion of patients who died within 30 and 90 days of their operation.

\section{Covariate definitions}

Data from HES provided information on comorbidity and ethnicity; all other covariate data fields were from the NLCA. Socioeconomic status was measured by postcode-derived Townsend index of material deprivation, in quintiles. ${ }^{12}$ We used our established method to calculate a Charlson comorbidity index using diagnoses recorded in patients' HES episodes any time before the procedure date. ${ }^{13}{ }^{14}$ Charlson index was grouped into four categories for analysis $(0,1,2-3$ and $\geq 4)$, as were percentage predicted forced expiratory volume in 1 second $\left(\mathrm{FEV}_{1}:>80 \%, 60-80 \%, 40-59 \%\right.$ and $\left.<40 \%\right)$ and $\mathrm{WHO}$ performance status (PS: 0, 1, 2 and 3-4). Stage and histological subtype were obtained from pretreatment records; if these data were missing we used post-treatment records.

\section{Statistical methods}

All statistical analyses were performed using Stata MP V.12 (StataCorp, Texas, USA). We calculated the percentages of patients who died within 30 and 90 days of surgery. To determine whether there were marked differences in the features of patients who died within the first 30 days after surgery and those who died between 31 and 90 days, we compared demographic, comorbid, tumour and procedure related features of patients who died in these two time periods.

We used logistic regression to estimate ORs associated with demographic, comorbid, tumour and procedure related factors for death within 30 days and within 90 days. We built a multivariate model including all factors that were significantly associated (defined as $p<0.1$ ) with death in univariate analysis and then assessed the significance of each variable in the multivariate model using a likelihood ratio test.

\section{Predictive score}

To calculate our predictive score we re-ran our model restricted to records with complete data on PS, stage and lung function. Because of the reduced power with this smaller sample we recoded Charlson index as a binary variable $(0-1, \geq 2)$ and age as $<55,55-65,66-75$ and $>75$ years. Our predictive score comprises the coefficients and constant from this model.

To demonstrate the function of this score, and to allow comparison with Thoracoscore, we applied both scores to hypothetical low, moderate and high risk cases.

\section{RESULTS}

There were 113261 patients with NSCLC in the NLCA database first seen between January 2004 and March 2010; 46013 with stage recorded as IIIB or IV and a further 102 who were aged less than 30 years at diagnosis were excluded. Of the remaining patients, 12269 had an OPCS-4 code for a potentially curative procedure in HES between 1 January 2004 and 31 March 2010. We excluded 292 patients for whom the difference between the procedure date recorded in the NLCA and that recorded in HES was >10 days, 437 who had an ICD-10 code for metastatic cancer recorded prior to the procedure date, and a further 549 for whom the procedure date was $>3$ months before or $>6$ months after the NLCA date of diagnosis, leaving 10991 patients for analysis.

The majority $(56 \%)$ of these patients were men, $20 \%$ were aged $70-74$ years and $31 \%$ had a PS of 0 (table 1). The most commonly performed procedure was lobectomy (64\%), with only $10 \%$ of patients having had a pneumonectomy. Twenty-eight per cent of patients had stage IB NSCLC, although $26 \%$ did not have a preoperative or postoperative stage recorded. The most common preoperative histological subtype was adenocarcinoma (31\%) followed by squamous cell (28\%). Twenty-one per cent did not have a record of preoperative or postoperative histology; in most cases this is likely to reflect missing data rather than the absence of histological confirmation of lung cancer.

\section{Mortality}

Three per cent of patients (334) died within 30 days of their procedure and a further $2.9 \%$ (313) between 31 and 90 days (therefore a total of $5.9 \%$ (647) died within 90 days). There were no statistically significant differences in patient, comorbidity or tumour factors between patients who died within 30 days of their procedure and those who died between 31 and 90 days (table 1). A higher proportion of those who died within 30 days had a pneumonectomy or bi-lobectomy compared with those who died between 31 and 90 days. Given these findings, we elected to report results for 90-day mortality for the remainder 
Table 1 Features of patients who died within 30 days and between 31 and 90 days after surgery

\begin{tabular}{|c|c|c|c|c|c|c|c|}
\hline & \multicolumn{2}{|c|}{ Overall $\mathrm{N}=10991$} & \multicolumn{2}{|c|}{$\begin{array}{l}\text { Died within } 30 \text { days } \\
(n=334)\end{array}$} & \multicolumn{2}{|c|}{$\begin{array}{l}\text { Died between } 31 \text { and } \\
90 \text { days }(n=313)\end{array}$} & \multirow[b]{2}{*}{$\chi^{2}$} \\
\hline & $\mathrm{n}$ & $\%$ & $\mathbf{n}$ & $\% *$ & $\mathrm{n}$ & $\% \dagger$ & \\
\hline \multicolumn{8}{|l|}{ Sex } \\
\hline Women & 4824 & 43.9 & 107 & 2.2 & 103 & 2.1 & \\
\hline Men & 6167 & 56.1 & 227 & 3.7 & 210 & 3.4 & $\mathrm{p}=0.813$ \\
\hline \multicolumn{8}{|l|}{ Age group } \\
\hline$<55$ & 1008 & 9.2 & 12 & 1.2 & 23 & 2.3 & \\
\hline $55-59$ & 1090 & 9.9 & 21 & 1.9 & 24 & 2.2 & \\
\hline $60-64$ & 1847 & 16.8 & 31 & 1.7 & 32 & 1.7 & \\
\hline $65-69$ & 2128 & 19.4 & 56 & 2.6 & 49 & 2.3 & \\
\hline $70-74$ & 2226 & 20.3 & 84 & 3.8 & 78 & 3.5 & \\
\hline $75-79$ & 1828 & 16.6 & 88 & 4.8 & 62 & 3.4 & \\
\hline $80-84$ & 730 & 6.6 & 34 & 4.7 & 35 & 4.8 & \\
\hline $85+$ & 134 & 1.2 & 12 & 9.0 & 10 & 7.5 & $p=0.331$ \\
\hline \multicolumn{8}{|l|}{ Ethnicity } \\
\hline White & 8983 & 81.7 & 254 & 2.8 & 256 & 2.8 & \\
\hline Black & 82 & 0.7 & 1 & 1.2 & 0 & 0.0 & \\
\hline Asian & 112 & 1.0 & 2 & 1.8 & 1 & 0.9 & \\
\hline Other & 77 & 0.7 & 1 & 1.3 & 2 & 2.6 & $p=0.643 \ddagger$ \\
\hline Missing & 1737 & 15.8 & 76 & 4.4 & 54 & 3.1 & $p=0.317$ \\
\hline \multicolumn{8}{|l|}{ Townsend quintile } \\
\hline 1 & 1343 & 12.2 & 36 & 2.7 & 30 & 2.2 & \\
\hline 2 & 1602 & 14.6 & 45 & 2.8 & 41 & 2.6 & \\
\hline 3 & 1609 & 14.6 & 52 & 3.2 & 46 & 2.9 & \\
\hline 4 & 1723 & 14.6 & 64 & 4.0 & 55 & 3.4 & \\
\hline (most deprived) 5 & 2074 & 15.7 & 74 & 4.3 & 58 & 3.4 & $p=0.985 \neq$ \\
\hline Missing & 2640 & 18.9 & 63 & 3.0 & 83 & 4.0 & $p=0.328$ \\
\hline \multicolumn{8}{|l|}{ Performance status } \\
\hline 0 & 3422 & 31.1 & 72 & 2.1 & 60 & 1.8 & \\
\hline 1 & 2815 & 25.6 & 84 & 3.0 & 93 & 3.3 & \\
\hline 2 & 465 & 4.2 & 23 & 4.9 & 28 & 6.0 & \\
\hline $3-4$ & 108 & 1.0 & 11 & 10.2 & 9 & 8.3 & $\mathrm{p}=0.524 \ddagger$ \\
\hline Missing & 4181 & 38.0 & 144 & 3.4 & 123 & 2.9 & $p=0.523$ \\
\hline \multicolumn{8}{|l|}{ Predicted FEV ${ }_{1}$} \\
\hline$>80 \%$ & 1891 & 17.2 & 34 & 1.8 & 39 & 2.1 & \\
\hline $60-79 \%$ & 1499 & 13.6 & 42 & 2.8 & 45 & 3.0 & \\
\hline $40-59 \%$ & 726 & 6.6 & 23 & 3.2 & 27 & 3.7 & \\
\hline$<40 \%$ & 141 & 1.3 & 5 & 3.5 & 7 & 5.0 & $\mathrm{p}=0.975 \ddagger$ \\
\hline Missing & 6734 & 61.3 & 230 & 3.4 & 195 & 2.9 & $p=0.508$ \\
\hline \multicolumn{8}{|l|}{ Charlson index } \\
\hline 0 & 5456 & 49.6 & 128 & 2.3 & 130 & 2.4 & \\
\hline 1 & 2791 & 25.4 & 87 & 3.1 & 84 & 3.0 & \\
\hline $2-3$ & 2233 & 20.3 & 95 & 4.3 & 81 & 3.6 & \\
\hline$\geq 4$ & 511 & 4.6 & 24 & 4.7 & 18 & 3.5 & $p=0.715$ \\
\hline \multicolumn{8}{|l|}{ Stage } \\
\hline IA & 2249 & 20.5 & 37 & 1.6 & 41 & 1.8 & \\
\hline IB & 3064 & 27.9 & 87 & 2.8 & 82 & 2.7 & \\
\hline IIA & 334 & 3.0 & 6 & 1.8 & 3 & 0.9 & \\
\hline IIB & 1494 & 13.6 & 55 & 3.7 & 47 & 3.1 & \\
\hline IIIA & 933 & 8.5 & 41 & 4.4 & 39 & 4.2 & $p=0.812 \ddagger$ \\
\hline Missing & 2857 & 26.0 & 108 & 3.8 & 101 & 3.5 & $p=0.903$ \\
\hline \multicolumn{8}{|l|}{ Side } \\
\hline Right & 5067 & 46.1 & 157 & 3.1 & 161 & 3.2 & \\
\hline Left & 3930 & 35.8 & 105 & 2.7 & 114 & 2.9 & \\
\hline Other & 85 & 0.8 & 5 & 5.9 & 4 & 4.7 & $p=0.875 \ddagger$ \\
\hline Missing & 1909 & 17.4 & 67 & 3.5 & 34 & 1.8 & $p=0.014$ \\
\hline
\end{tabular}


Table 1 Continued

\begin{tabular}{|c|c|c|c|c|c|c|c|}
\hline & \multicolumn{2}{|c|}{ Overall $\mathrm{N}=10991$} & \multicolumn{2}{|c|}{$\begin{array}{l}\text { Died within } 30 \text { days } \\
(n=334)\end{array}$} & \multicolumn{2}{|c|}{$\begin{array}{l}\text { Died between } 31 \text { and } \\
90 \text { days }(n=313)\end{array}$} & \multirow[b]{2}{*}{$\chi^{2}$} \\
\hline & $n$ & $\%$ & $\mathbf{n}$ & $\% *$ & $\mathbf{n}$ & $\% \dagger$ & \\
\hline \multicolumn{8}{|l|}{ Histology } \\
\hline Adenocarcinoma & 3406 & 31.0 & 60 & 1.8 & 75 & 2.2 & \\
\hline Squamous cell & 3106 & 28.3 & 125 & 4.0 & 107 & 3.4 & \\
\hline NSCLC NOS & 1833 & 16.7 & 62 & 3.4 & 62 & 3.4 & \\
\hline Other & 368 & 3.3 & 10 & 2.7 & 12 & 3.3 & $p=0.356 \ddagger$ \\
\hline Missing & 2278 & 20.7 & 77 & 3.4 & 57 & 2.5 & $p=0.235$ \\
\hline \multicolumn{8}{|l|}{ Procedure } \\
\hline Segmentectomy/wedge & 1671 & 15.2 & 35 & 2.1 & 35 & 2.1 & \\
\hline Lobectomy & 7051 & 64.2 & 160 & 2.3 & 165 & 2.3 & \\
\hline Bi-lobectomy & 431 & 3.9 & 25 & 5.8 & 13 & 3.0 & \\
\hline Pneumonectomy & 1121 & 10.2 & 78 & 7.0 & 51 & 4.5 & \\
\hline Other & 717 & 6.5 & 36 & 5.0 & 49 & 6.8 & $p=0.028$ \\
\hline
\end{tabular}

of this paper; the results for death within 30 days of surgery are similar and can be found in online supplementary table A.

Within 90 days of surgery, men were more likely to die than women $(7.1 \%$ vs $4.4 \%)$ and the proportion of patients who died after pneumonectomy was higher than for lobectomy $(11.5 \%$ vs $4.6 \%)$ (table 2). Sixteen per cent of patients over 85 years and $18.5 \%$ of those with PS $3-4$ died within this postoperative period. Age was strongly associated with postoperative mortality: Compared with a patient aged $70-74$ years, the odds of death within 90 days of surgery for a patient aged $>85$ years were markedly increased, even after accounting for other demographic, tumour and comorbidity factors (adjusted OR 2.84, 95\% CI 1.71 to 4.71 ) (table 2). The next most strongly associated factors were procedure type and PS. Significant associations were also observed with percentage predicted forced expiratory volume in $1 \mathrm{~s}\left(\mathrm{FEV}_{1}\right)$, stage, Charlson index, Townsend score, ethnicity, histological subtype and sex.

There were 3319 patients with complete data on PS, stage and lung function. The proportions of these patients who died within 30 and 90 days of surgery were slightly lower $(2.5 \%$ and

Table 2 Factors associated with death within 90 days of surgery

\begin{tabular}{|c|c|c|c|c|c|c|c|c|}
\hline & \multicolumn{2}{|c|}{ Overall $\mathrm{N}=10991$} & \multicolumn{4}{|c|}{ Died within 90 days of surgery $(n=647)$} & \multirow[b]{2}{*}{ Adjusted OR* } & \multirow[b]{2}{*}{$95 \% \mathrm{Cl}$} \\
\hline & $\mathbf{n}$ & $\%$ & $\mathrm{n}$ & $\%$ & OR & $95 \% \mathrm{Cl}$ & & \\
\hline \multicolumn{9}{|l|}{ Sex } \\
\hline Women & 4824 & 43.9 & 210 & 4.4 & 1.00 & & 1.00 & \\
\hline Men & 6167 & 56.1 & 437 & 7.1 & 1.68 & $\begin{array}{l}1.42 \text { to } 1.98 \\
p<0.0001\end{array}$ & 1.37 & $\begin{array}{l}1.15 \text { to } 1.63 \\
p=0.0004\end{array}$ \\
\hline \multicolumn{9}{|l|}{ Age group } \\
\hline$<55$ & 1008 & 9.2 & 35 & 3.5 & 0.46 & 0.32 to 0.67 & 0.46 & 0.32 to 0.68 \\
\hline $55-59$ & 1090 & 9.9 & 45 & 4.1 & 0.55 & 0.39 to 0.77 & 0.53 & 0.37 to 0.75 \\
\hline $60-64$ & 1847 & 16.8 & 63 & 3.4 & 0.45 & 0.33 to 0.61 & 0.44 & 0.32 to 0.59 \\
\hline $65-69$ & 2128 & 19.4 & 105 & 4.9 & 0.63 & 0.49 to 0.82 & 0.61 & 0.47 to 0.79 \\
\hline $70-74$ & 2226 & 20.3 & 162 & 7.3 & 1.00 & & 1.00 & \\
\hline $75-79$ & 1828 & 16.6 & 150 & 8.2 & 1.14 & 0.90 to 1.44 & 1.19 & 0.94 to 1.51 \\
\hline $80-84$ & 730 & 6.6 & 69 & 9.5 & 1.33 & 0.99 to 1.79 & 1.46 & 1.07 to 1.98 \\
\hline $85+$ & 134 & 1.2 & 22 & 16.4 & 2.50 & $\begin{array}{l}1.54 \text { to } 4.06 \\
p<0.0001^{* *}\end{array}$ & 2.84 & $\begin{array}{l}1.71 \text { to } 4.71 \\
p<0.0001^{\text {** }}\end{array}$ \\
\hline \multicolumn{9}{|l|}{ Ethnicity } \\
\hline White & 8983 & 81.7 & 510 & 5.7 & 1.00 & & 1.00 & \\
\hline Black & 82 & 0.7 & 1 & 1.2 & 0.21 & 0.03 to 1.48 & 0.21 & 0.03 to 1.51 \\
\hline Asian & 112 & 1.0 & 3 & 2.7 & 0.46 & 0.14 to 1.44 & 0.45 & 0.14 to 1.46 \\
\hline Other & 77 & 0.7 & 3 & 3.9 & 0.67 & 0.21 to 2.14 & 0.71 & 0.22 to 2.31 \\
\hline Missing & 1737 & 15.8 & 130 & 7.5 & 1.34 & $\begin{array}{l}1.10 \text { to } 1.64 \\
p=0.0030\end{array}$ & 1.46 & $\begin{array}{l}1.19 \text { to } 1.80 \\
p=0.0005\end{array}$ \\
\hline
\end{tabular}


Table 2 Continued

\begin{tabular}{|c|c|c|c|c|c|c|c|c|}
\hline & \multicolumn{2}{|c|}{ Overall $\mathrm{N}=10991$} & \multicolumn{4}{|c|}{ Died within 90 days of surgery $(n=647)$} & \multirow[b]{2}{*}{ Adjusted OR* } & \multirow[b]{2}{*}{$95 \% \mathrm{Cl}$} \\
\hline & $\mathrm{n}$ & $\%$ & $\mathrm{n}$ & $\%$ & OR & $95 \% \mathrm{Cl}$ & & \\
\hline \multicolumn{9}{|l|}{ Townsend quintile } \\
\hline 1 & 1343 & 12.2 & 66 & 4.9 & 1.00 & & 1.00 & \\
\hline 2 & 1602 & 14.6 & 86 & 5.4 & 1.10 & 0.79 to 1.53 & 1.12 & 0.80 to 1.57 \\
\hline 3 & 1609 & 14.6 & 98 & 6.1 & 1.25 & 0.91 to 1.73 & 1.35 & 0.97 to 1.88 \\
\hline 4 & 1723 & 14.6 & 119 & 6.9 & 1.44 & 1.05 to 1.96 & 1.59 & 1.16 to 2.19 \\
\hline (most deprived) 5 & 2074 & 15.7 & 132 & 6.4 & 1.32 & 0.97 to 1.78 & 1.45 & 1.06 to 1.99 \\
\hline \multirow[t]{2}{*}{ Missing } & 2640 & 18.9 & 146 & 5.5 & 1.13 & 0.84 to 1.53 & 1.13 & 0.83 to 1.55 \\
\hline & & & & & & $\mathrm{p}=0.0221$ * * & & $\mathrm{p}=0.0028^{* *}$ \\
\hline \multicolumn{9}{|l|}{ Performance status } \\
\hline 0 & 3422 & 31.1 & 132 & 3.9 & 1.00 & & 1.00 & \\
\hline 1 & 2815 & 25.6 & 177 & 6.3 & 1.67 & 1.33 to 2.11 & 1.38 & 1.09 to 1.75 \\
\hline 2 & 465 & 4.2 & 51 & 11.0 & 3.07 & 2.19 to 4.31 & 2.40 & 1.68 to 3.41 \\
\hline $3-4$ & 108 & 1.0 & 20 & 18.5 & 5.66 & 3.38 to 9.49 & 4.08 & 2.37 to 7.02 \\
\hline \multirow[t]{2}{*}{ Missing } & 4181 & 38.0 & 267 & 6.4 & 1.70 & 1.37 to 2.11 & 1.35 & 1.06 to 1.73 \\
\hline & & & & & & $\mathrm{p}<0.0001$ ** & & $\mathrm{p}<0.0001^{* *}$ \\
\hline \multicolumn{9}{|l|}{ Predicted $\mathrm{FEV}_{1}$} \\
\hline$>80 \%$ & 1891 & 17.2 & 73 & 3.9 & 1.00 & & 1.00 & \\
\hline $60-79 \%$ & 1499 & 13.6 & 87 & 5.8 & 1.53 & 1.12 to 2.11 & 1.37 & 0.99 to 1.90 \\
\hline $40-59 \%$ & 726 & 6.6 & 50 & 6.9 & 1.84 & 1.27 to 2.67 & 1.64 & 1.12 to 2.41 \\
\hline$<40 \%$ & 141 & 1.3 & 12 & 8.5 & 2.32 & 1.23 to 4.38 & 2.07 & 1.06 to 4.04 \\
\hline \multirow[t]{2}{*}{ Missing } & 6734 & 61.3 & 425 & 6.3 & 1.68 & 1.30 to 2.16 & 1.48 & 1.13 to 1.95 \\
\hline & & & & & & $\mathrm{p}=0.0002^{* *}$ & & $\mathrm{p}=0.0020^{* *}$ \\
\hline \multicolumn{9}{|l|}{ Charlson index } \\
\hline 0 & 5456 & 49.6 & 258 & 4.7 & 1.00 & & 1.00 & \\
\hline 1 & 2791 & 25.4 & 171 & 6.1 & 1.31 & 1.08 to 1.60 & 1.20 & 0.98 to 1.48 \\
\hline $2-3$ & 2233 & 20.3 & 176 & 7.9 & 1.72 & 1.41 to 2.10 & 1.54 & 1.25 to 1.90 \\
\hline \multirow[t]{2}{*}{$\geq 4$} & 511 & 4.6 & 42 & 8.2 & 1.80 & 1.28 to 2.53 & 1.53 & 1.07 to 2.18 \\
\hline & & & & & & $\mathrm{p}<0.0001 * *$ & & $\mathrm{p}<0.0001$ * * \\
\hline \multicolumn{9}{|l|}{ Stage } \\
\hline $\mathrm{IA}$ & 2249 & 20.5 & 78 & 3.5 & 1.00 & & 1.00 & \\
\hline IB & 3064 & 27.9 & 169 & 5.5 & 1.62 & 1.24 to 2.14 & 1.39 & 1.05 to 1.84 \\
\hline$\| A$ & 334 & 3.0 & 9 & 2.7 & 0.77 & 0.38 to 1.55 & 0.67 & 0.33 to 1.37 \\
\hline IIB & 1494 & 13.6 & 102 & 6.8 & 2.04 & 1.51 to 2.76 & 1.59 & 1.16 to 2.19 \\
\hline IIIA & 933 & 8.5 & 80 & 8.6 & 2.44 & 1.77 to 3.36 & 1.85 & 1.32 to 2.60 \\
\hline \multirow[t]{2}{*}{ Missing } & 2857 & 26.0 & 209 & 7.3 & 2.20 & 1.68 to 2.87 & 1.78 & 1.32 to 2.41 \\
\hline & & & & & & $\mathrm{p}<0.0001$ ** & & $p=0.0004^{* *}$ \\
\hline \multicolumn{9}{|l|}{ Side } \\
\hline Right & 5067 & 46.1 & 318 & 6.3 & 1.00 & & & \\
\hline Left & 3930 & 35.8 & 219 & 5.6 & 0.88 & 0.74 to 1.05 & & \\
\hline Other & 85 & 0.8 & 9 & 10.6 & 1.77 & 0.88 to 3.56 & & \\
\hline \multirow[t]{2}{*}{ Missing } & 1909 & 17.4 & 101 & 5.3 & 0.83 & 0.66 to 1.05 & & \\
\hline & & & & & & $p=0.1063$ & & \\
\hline Histology & & & & & & & & \\
\hline Adenocarcinoma & 3406 & 31.0 & 135 & 4.0 & 1.00 & & 1.00 & \\
\hline Squamous cell & 3106 & 28.3 & 232 & 7.5 & 1.96 & 1.57 to 2.43 & 1.38 & 1.10 to 1.73 \\
\hline NSCLC NOS & 1833 & 16.7 & 124 & 6.8 & 1.76 & 1.37 to 2.26 & 1.36 & 1.05 to 1.76 \\
\hline Other & 368 & 3.3 & 22 & 6.0 & 1.54 & 0.97 to 2.45 & 1.14 & 0.70 to 1.84 \\
\hline Missing & 2278 & 20.7 & 134 & 5.9 & 1.51 & 1.19 to 1.94 & 1.08 & 0.82 to 1.42 \\
\hline & & & & & & $p<0.0001$ & & $\mathrm{p}=0.0420$ \\
\hline Procedure & & & & & & & & \\
\hline Segmentectomy/wedge & 1671 & 15.2 & 70 & 4.2 & 0.90 & 0.69 to 1.16 & 0.80 & 0.61 to 1.05 \\
\hline Lobectomy & 7051 & 64.2 & 325 & 4.6 & 1.00 & & 1.00 & \\
\hline Bi-lobectomy & 431 & 3.9 & 38 & 8.8 & 2.00 & 1.41 to 2.84 & 1.94 & 1.35 to 2.78 \\
\hline Pneumonectomy & 1121 & 10.2 & 129 & 11.5 & 2.69 & 2.17 to 3.33 & 2.81 & 2.22 to 3.56 \\
\hline Other & 717 & 6.5 & 85 & 11.9 & 2.78 & 2.16 to 3.57 & 2.12 & 1.62 to 2.77 \\
\hline & & & & & & $p<0.0001$ & & $p<0.0001$ \\
\hline
\end{tabular}

${ }^{*}$ ORs are adjusted for all other factors for which adjusted ORs are given. All $p$ values calculated using likelihood ratio test.

** Likelihood ratio test $\mathrm{p}$ for trend.

$\mathrm{FEV}_{1}$, forced expiratory volume in $1 \mathrm{~s}$; NSCLC, non-small cell lung cancer; NOS, not otherwise specified. 
$5.1 \%$ ) than in the overall population of 10991 , however in multivariate analysis age, procedure type, PS, stage, Charlson index and $\mathrm{FEV}_{1}$ were again found to be significantly associated with early postoperative death, with similar ORs to the initial analysis (table 3 and online supplementary table B). Sex, ethnicity, Townsend quintile and histological subtype were not independently associated with 90-day mortality in this analysis but given the ease of accurately recording sex we retained this variable in our final model.

The coefficients and constant from our multivariate model are presented in table 4 , and these are the values we have used in our predictive score. For comparison we also present similar information for Thoracoscore. Table 5 shows the predicted outcomes using our score and Thoracoscore for three hypothetical cases. Predicted mortality using our score was very similar to that of Thoracoscore for the low-risk patient, slightly higher for medium risk and almost double for the high-risk patient.

\section{DISCUSSION}

For people undergoing surgical resection with curative intent for NSCLC, we found postoperative mortality to be $3.0 \%$ within 30 days and $5.9 \%$ within 90 days. Patient demographic, comorbidity and tumour-related features were similar whether we considered those who died within 30 days or 31-90 days after surgery; we suggest that 90-day mortality risk should be considered by patients and doctors prior to surgery. Increasing age, PS and procedure type were strongly associated with an increased risk of early postoperative death.

We were able to use data from the NLCA to develop a predictive score which provides an estimate of the risk of 90-day mortality after thoracic surgery specifically for lung cancer. This score requires assessment in other cohorts, but has potential to greatly improve the information available to patients and clinicians prior to surgery.

\section{Strengths and weaknesses}

The main strengths of our study are the large sample size and the representative nature of the cases included. As far as we are aware this is the largest study of postoperative mortality in lung cancer based on a UK population. There are few previous reports of 90-day mortality after lung cancer surgery and, to our knowledge, no predictive scores based on this outcome.

Whilst case ascertainment has improved and the number of records with missing data has declined since the NLCA was established in $2004,{ }^{15}$ the main weakness of this study remains the missing data. The variable with the greatest proportion of missing data was lung function (percentage predicted $\mathrm{FEV}_{1}$ was missing in $61 \%$ of cases). It is unlikely that these patients underwent thoracic surgery without prior measurement of their lung function, and the data are probably missing because they were not available to administrative staff at the time of data entry. We analysed all variables using a separate category for missing data

Table 3 Factors associated with death within 90 days of surgery for patients with records of performance status, stage and lung function

\begin{tabular}{|c|c|c|c|c|c|c|c|c|}
\hline & \multicolumn{2}{|c|}{ Overall $\mathrm{N}=3319$} & \multicolumn{4}{|c|}{ Died within 90 days of surgery $(n=169)$} & \multirow[b]{2}{*}{ Adjusted $\mathrm{OR}^{*}$} & \multirow[b]{2}{*}{$95 \% \mathrm{Cl}$} \\
\hline & $\mathbf{n}$ & $\%$ & $\mathrm{n}$ & $\%$ & OR & $95 \% \mathrm{Cl}$ & & \\
\hline \multicolumn{9}{|l|}{ Sex } \\
\hline Women & 1482 & 44.7 & 57 & 3.8 & 1.00 & & 1.00 & \\
\hline Men & 1837 & 55.3 & 112 & 6.1 & 1.62 & $\begin{array}{l}1.17 \text { to } 2.25 \\
p=0.0030\end{array}$ & 1.24 & $\begin{array}{l}0.88 \text { to } 1.75 \\
p=0.2196\end{array}$ \\
\hline \multicolumn{9}{|l|}{ Age group } \\
\hline$<55$ & 268 & 8.1 & 5 & 1.9 & 0.27 & 0.11 to 0.68 & 0.32 & 0.12 to 0.83 \\
\hline $55-59$ & 272 & 8.2 & 8 & 2.9 & 0.43 & 0.20 to 0.92 & 0.40 & 0.18 to 0.88 \\
\hline $60-64$ & 583 & 17.6 & 18 & 3.1 & 0.45 & 0.26 to 0.78 & 0.45 & 0.25 to 0.80 \\
\hline $65-69$ & 665 & 20.0 & 29 & 4.4 & 0.64 & 0.40 to 1.04 & 0.61 & 0.37 to 1.00 \\
\hline $70-74$ & 694 & 20.9 & 46 & 6.6 & 1.00 & & 1.00 & \\
\hline $75-79$ & 566 & 17.1 & 40 & 7.1 & 1.07 & 0.69 to 1.66 & 1.15 & 0.73 to 1.82 \\
\hline $80-84$ & 236 & 7.1 & 18 & 7.6 & 1.16 & 0.66 to 2.05 & 1.43 & 0.80 to 2.58 \\
\hline \multirow[t]{2}{*}{$85+$} & 35 & 1.1 & 5 & 14.3 & 2.35 & 0.87 to 6.34 & 3.17 & 1.12 to 9.01 \\
\hline & & & & & & $\mathrm{p}<0.0001^{* *}$ & & $p<0.0001^{* *}$ \\
\hline \multicolumn{9}{|l|}{ Ethnicity } \\
\hline White & 2769 & 83.4 & 146 & 5.3 & 1.00 & & & \\
\hline Black & 21 & 0.6 & - & - & & & & \\
\hline Asian & 28 & 0.8 & - & - & & & & \\
\hline Other & 24 & 0.7 & - & - & & & & \\
\hline Missing & 477 & 14.4 & 23 & 4.8 & 0.91 & 0.58 to 1.43 & & \\
\hline \multicolumn{9}{|l|}{ Townsend quintile } \\
\hline 1 & 448 & 13.5 & 14 & 3.1 & 1.00 & & & \\
\hline 2 & 512 & 15.4 & 23 & 4.5 & 1.46 & 0.74 to 2.87 & & \\
\hline 3 & 531 & 16.0 & 39 & 7.3 & 2.46 & 1.32 to 4.59 & & \\
\hline 4 & 615 & 18.5 & 28 & 4.6 & 1.48 & 0.77 to 2.84 & & \\
\hline (most deprived) 5 & 772 & 23.3 & 38 & 4.9 & 1.60 & 0.86 to 3.00 & & \\
\hline \multirow[t]{2}{*}{ Missing } & 441 & 13.3 & 27 & 6.1 & 2.02 & 1.05 to 3.91 & & \\
\hline & & & & & & $\mathrm{p}=0.3325^{* *}$ & & \\
\hline
\end{tabular}


Table 3 Continued

\begin{tabular}{|c|c|c|c|c|c|c|c|c|}
\hline & \multicolumn{2}{|c|}{ Overall $\mathrm{N}=3319$} & \multicolumn{4}{|c|}{ Died within 90 days of surgery $(n=169)$} & \multirow[b]{2}{*}{ Adjusted $\mathrm{OR}^{*}$} & \multirow[b]{2}{*}{$95 \% \mathrm{Cl}$} \\
\hline & $\mathrm{n}$ & $\%$ & n & $\%$ & OR & $95 \% \mathrm{Cl}$ & & \\
\hline \multicolumn{9}{|l|}{ Performance status } \\
\hline 0 & 1674 & 50.4 & 51 & 3.0 & 1.00 & & 1.00 & \\
\hline 1 & 1390 & 41.9 & 97 & 7.0 & 2.39 & 1.69 to 3.38 & 1.89 & 1.31 to 2.72 \\
\hline 2 & 215 & 6.5 & 19 & 8.8 & 3.08 & 1.78 to 5.33 & 2.39 & 1.34 to 4.28 \\
\hline \multirow[t]{2}{*}{$3-4$} & 40 & 1.2 & 2 & 5.0 & 1.67 & 0.39 to 7.13 & 1.67 & 0.27 to 5.11 \\
\hline & & & & & & $\mathrm{p}<0.0001^{* *}$ & & $\mathrm{p}=0.0055^{* *}$ \\
\hline \multicolumn{9}{|l|}{ Predicted FEV 1} \\
\hline$>80 \%$ & 1508 & 45.4 & 58 & 3.8 & 1.00 & & 1.00 & \\
\hline $60-79 \%$ & 1145 & 34.5 & 58 & 5.1 & 1.33 & 0.92 to 1.94 & 1.25 & 0.85 to 1.84 \\
\hline $40-59 \%$ & 557 & 16.8 & 43 & 7.7 & 2.09 & 1.39 to 3.14 & 2.01 & 1.30 to 3.10 \\
\hline \multirow[t]{2}{*}{$<40 \%$} & 109 & 3.3 & 10 & 9.2 & 2.53 & 1.25 to 5.09 & 2.78 & 1.31 to 5.88 \\
\hline & & & & & & $\mathrm{p}=0.0001^{* *}$ & & $\mathrm{p}=0.0004^{* *}$ \\
\hline \multicolumn{9}{|l|}{ Charlson index } \\
\hline $0-1$ & 2508 & 75.6 & 115 & 4.6 & 1.00 & & 1.00 & \\
\hline \multirow[t]{2}{*}{$\geq 2$} & 811 & 24.4 & 54 & 6.7 & 1.22 & 1.03 to 1.44 & 1.19 & 1.00 to 1.42 \\
\hline & & & & & & $\mathrm{p}=0.0233^{* *}$ & & $\mathrm{p}=0.0514$ \\
\hline \multicolumn{9}{|l|}{ Stage } \\
\hline $\mathrm{IA}$ & 949 & 28.6 & 30 & 3.2 & 1.00 & & 1.00 & \\
\hline IB & 1237 & 37.3 & 63 & 5.1 & 1.64 & 1.06 to 2.56 & 1.42 & 0.90 to 2.25 \\
\hline$\| \mathrm{A}$ & 131 & 3.9 & 4 & 3.1 & 0.96 & 0.33 to 2.78 & 0.77 & 0.26 to 2.27 \\
\hline IIB & 614 & 18.5 & 41 & 6.7 & 2.19 & 1.35 to 3.55 & 1.70 & 1.01 to 2.87 \\
\hline \multirow[t]{2}{*}{ IIIA } & 388 & 11.7 & 31 & 8.0 & 2.66 & 1.59 to 4.46 & 2.18 & 1.25 to 3.81 \\
\hline & & & & & & $\mathrm{p}=0.0001 * *$ & & $\mathrm{p}=0.0085^{* *}$ \\
\hline \multicolumn{9}{|l|}{ Side } \\
\hline Right & 1841 & 55.5 & 96 & 5.2 & 1.00 & & & \\
\hline Left & 1365 & 41.1 & 64 & 4.7 & 0.89 & 0.65 to 1.24 & & \\
\hline Other & 18 & 0.5 & 1 & 5.6 & 1.07 & 0.14 to 8.12 & & \\
\hline \multirow[t]{2}{*}{ Missing } & 95 & 2.9 & 8 & 8.4 & 1.67 & 0.79 to 3.55 & & \\
\hline & & & & & & $\mathrm{p}=0.4988$ & & \\
\hline \multicolumn{9}{|l|}{ Histology (preoperative) } \\
\hline Adenocarcinoma & 1155 & 34.8 & 43 & 3.7 & 1.00 & & 1.00 & \\
\hline Squamous cell & 1151 & 34.7 & 74 & 6.4 & 1.78 & 1.21 to 2.61 & 1.08 & 0.72 to 1.63 \\
\hline NSCLC NOS & 662 & 19.9 & 35 & 5.3 & 1.44 & 0.91 to 2.28 & 1.03 & 0.64 to 1.66 \\
\hline Other & 82 & 2.5 & 3 & 3.7 & 0.98 & 0.30 to 3.24 & 0.83 & 0.25 to 2.82 \\
\hline \multirow[t]{2}{*}{ Missing } & 269 & 8.1 & 14 & 5.2 & 1.42 & 0.77 to 2.63 & 1.37 & 0.73 to 2.60 \\
\hline & & & & & & $p=0.0538$ & & $p=0.8873$ \\
\hline \multicolumn{9}{|l|}{ Procedure } \\
\hline Segmentectomy/wedge & 441 & 13.3 & 16 & 3.6 & 0.88 & 0.51 to 1.52 & 0.76 & 0.44 to 1.33 \\
\hline Lobectomy & 2275 & 68.5 & 93 & 4.1 & 1.00 & & 1.00 & \\
\hline Bi-lobectomy & 131 & 3.9 & 12 & 9.2 & 2.37 & 1.26 to 4.44 & 2.37 & 1.23 to 4.60 \\
\hline Pneumonectomy & 335 & 10.1 & 40 & 11.9 & 3.18 & 2.15 to 4.70 & 3.36 & 2.17 to 5.20 \\
\hline \multirow[t]{2}{*}{ Other } & 137 & 4.1 & 8 & 5.8 & 1.46 & 0.69 to 3.06 & 1.10 & 0.51 to 2.36 \\
\hline & & & & & & $\mathrm{p}<0.0001$ & & $\mathrm{p}<0.0001$ \\
\hline
\end{tabular}

${ }^{*}$ ORs are adjusted for all other factors for which adjusted ORs are given. All $p$ values calculated using likelihood ratio test.

** Likelihood ratio test $\mathrm{p}$ for trend.

$\mathrm{FEV}_{1}$, forced expiratory volume in $1 \mathrm{~s}$; NSCLC, non-small cell lung cancer; NOS, not otherwise specified; PS, performance status.

to ensure that the results were a true representation of the available data and, given the size of our study, we were still able to analyse data on lung function for over 4000 individuals. The UK lung cancer population is predominantly white and therefore we did not have sufficient power to detect any associations between ethnicity and outcome in this study.

We identified surgical procedures using HES coding, the accuracy of which is audited annually. ${ }^{16}$ When calculating Charlson index we assigned a score of zero to any individual who either had no records of hospital admission in the HES database, or had no record of an ICD-10 code relating to any of the diagnoses in the Charlson index. ${ }^{14}$ This method may have missed diagnoses which were only recorded in primary care; however $95 \%$ of patients had at least one inpatient episode prior to their procedure date and all relevant or major comorbidities should be recorded in each episode.

\section{Comparison with previous studies}

90-day mortality

There are few previous reports of 90-day mortality following surgery for lung cancer. One Dutch group reported $3.9 \%$ 30-day and 6.8\% 90-day mortality after lobectomy, 
Table 4 Coefficients from multivariate model using NLCA data and from Thoracoscore

\begin{tabular}{|c|c|c|}
\hline & \multicolumn{2}{|l|}{ Coefficient } \\
\hline & Thoracoscore ${ }^{6}$ & NLCA data \\
\hline Definition of early mortality & 30 days or in hospital & 90 days \\
\hline Number of deaths & 218 & 169 \\
\hline \multicolumn{3}{|l|}{ Age (years) } \\
\hline$<55$ & - & - \\
\hline $55-65$ & 0.77 & 0.31 \\
\hline$>65$ & 1.01 & \\
\hline $66-75$ & & 0.97 \\
\hline$>75$ & & 1.40 \\
\hline \multicolumn{3}{|l|}{ Sex } \\
\hline Women & - & - \\
\hline Men & 0.45 & 0.23 \\
\hline \multicolumn{3}{|l|}{ ASA score } \\
\hline$\leq 2$ & - & \\
\hline$\geq 3$ & 0.61 & \\
\hline \multicolumn{3}{|l|}{ Performance status } \\
\hline 0 & & - \\
\hline$\leq 2$ & - & \\
\hline $1-2$ & & 0.68 \\
\hline$\geq 3$ & 0.69 & $0.21^{*}$ \\
\hline \multicolumn{3}{|l|}{ MRC dyspnoea score } \\
\hline$\leq 2$ & - & \\
\hline$\geq 3$ & 0.91 & \\
\hline \multicolumn{3}{|l|}{$\%$ predicted $\mathrm{FEV}_{1}$} \\
\hline$>80 \%$ & & - \\
\hline $61-80 \%$ & & 0.20 \\
\hline $40-60 \%$ & & 0.69 \\
\hline$<40 \%$ & & 0.95 \\
\hline \multicolumn{3}{|l|}{ Priority } \\
\hline Elective & - & \\
\hline Urgent/emergency & 0.84 & \\
\hline \multicolumn{3}{|l|}{ Procedure class } \\
\hline Othert & - & \\
\hline (Bi-)lobectomy, wedge or segmentectomy & & - \\
\hline Other $¥$ & & 0.07 \\
\hline Pneumonectomy & 1.22 & 1.16 \\
\hline \multicolumn{3}{|l|}{ Diagnosis group } \\
\hline Benign & - & \\
\hline Malignant & 1.24 & \\
\hline \multicolumn{3}{|l|}{ Comorbidity score§ } \\
\hline 0 & - & \\
\hline $1-2$ & 0.74 & \\
\hline$\geq 3$ & 0.91 & \\
\hline \multicolumn{3}{|l|}{ Charlson index } \\
\hline $0-1$ & & - \\
\hline$\geq 2$ & & 0.33 \\
\hline \multicolumn{3}{|l|}{ Stage } \\
\hline $\mathrm{IA}$ & & - \\
\hline IB & & 0.42 \\
\hline IIA or IIB & & 0.51 \\
\hline IIIA & & 0.84 \\
\hline Constant & -7.37 & -5.28 \\
\hline
\end{tabular}

* Only 40 patients and two deaths in this group.

tOther includes mediastinoscopy or other mediastinal surgery, wedge resection, lobectomy or bi-lobectomy.

$\ddagger 0$ ther includes procedures listed in online supplementary appendix A. Odds=exp (total of coefficients+constant); probability of death=odds/(1+odds).

$\S$ Number of significant comorbid conditions, including smoking, history of cancer, chronic obstructive pulmonary disease, diabetes mellitus, arterial hypertension, peripheral vascular disease, obesity and alcoholism.

ASA, American Society of Anaesthesiologists; FEV 1 , forced expiratory volume in $1 \mathrm{~s}$; MRC, Medical Research Council; NLCA, National Lung Cancer Audit; -, indicates baseline group.

bi-lobectomy or pneumonectomy between 2000 and 2008. ${ }^{17}$ These figures are comparable to ours.
Almost as many people died between 31 and 90 days as in the first 30 days after lung cancer resection in our study. Many previous studies included death prior to hospital discharge in their definition of 30-day mortality to account for people who were alive longer than 30 days due to improvements in perioperative management and intensive care. Discharge practices, however, vary between hospitals, and there remain a substantial proportion of patients who die after discharge but before 90 days. ${ }^{18}$ One of the important findings from our study is that the features of patients who die within the first 30 days of surgery are no different to those of patients who die between 31 and 90 days postoperatively. Since postoperative recovery takes several months, we suggest that patients should be provided with an estimate of their risk of death within 3 months, instead or as well as within 1 month.

\section{Comparison with Thoracoscore}

The discrepancies between mortality risk estimates using our score and Thoracoscore (table 5) are likely to be due to the longer time period in our study (deaths within 90 days compared with deaths in hospital) and the differences in populations studied. The overall in-hospital mortality using the data on which Thoracoscore was based was 2.2\% (218 deaths) compared with 5.1\% 90-day mortality (169 deaths in the non-missing dataset) in our study.

The Epithor database, which was used for Thoracoscore, includes data on American Society of Anaesthesiologists (ASA) score and Medical Research Council (MRC) dyspnoea score, both of which are components of Thoracoscore but are not recorded in the NLCA. Our score includes stage and lung function but while these data were available to the authors of Thoracoscore they did not find them to be significantly associated with in-hospital mortality, perhaps due to the better overall health of their cohort of patients. In addition, Thoracoscore uses age categories $<55,55-64$ and $>64$ years, and was developed using a dataset in which the mean age at operation was 54.7 years. In the UK, $75 \%$ of people diagnosed with lung cancer are over 65 years of age, ${ }^{19}$ and the number of older patients undergoing surgical resection for lung cancer is increasing. ${ }^{20}$ The mean age of patients in our dataset was 67 years.

A small study of lung cancer resections in England adds to concerns that Thoracoscore may not have good predictive ability for people with lung cancer. ${ }^{7}$ Neither score has been validated in a large study of patients with lung cancer, and prospective evaluation needs to be undertaken as a matter of priority. If our score proves to be a useful clinical tool, care must be taken when applying it to people of non-white ethnicity given that they contributed such a small proportion of our study data (of note, this is also likely to be the case for Thoracoscore, although ethnicity is not reported in the publication by Falcoz et $a l^{6}$ ).

\section{Other predictive models}

We compared our predictive score with Thoracoscore because it is recommended in national guidelines, ${ }^{5}$ however risk factors have also been assessed in other studies, including the European Thoracic Surgery Database Project, from which the European Societies Subjective Score (ESSS) was developed. ${ }^{2}$ This study included 3426 patients of whom 66 died in hospital, and the ESSS comprises age, MRC dyspnoea score, ASA score and procedure type. Two of the four components of the ESSS model are subjectively assessed; we only included one such measure (PS) and Thoracoscore includes all three. The authors of the ESSS were concerned that their tool included predominantly subjective measures and so used a subgroup of 1753 patients to develop a score based on age and predicted postoperative $\mathrm{FEV}_{1}$. 
Table 5 Patient features and predicted outcomes

Description of patient

Low risk: 56-year-old woman, MRC 1, ASA 2, PS 0, FEV $181 \%$, hypertension, ex-smoker, NSCLC stage IB, elective lobectomy

Moderate risk: 70-year-old man, MRC 2, ASA 3, PS 1, FEV $165 \%$, COPD,

hypertension, smoker, NSCLC stage IIB, elective lobectomy

High risk: 81-year-old man, MRC 4, ASA 3, PS 2, FEV $150 \%$, COPD, ischaemic heart disease,

hypertension, ex-smoker, diabetes, NSCLC stage IIB, elective pneumonectomy
Estimated risk of death (\%)

90-day mortality (NLCA score) In-hospital mortality (Thoracoscore)

90-day mortality (NLCA score)

In-hospital mortality (Thoracoscore)

90-day mortality (NLCA score)

In-hospital mortality (Thoracoscore)

\section{Clinical relevance}

The proportions of patients who die after potentially curative surgery for NSCLC are 3.0\% within 30 days and 5.9\% within 90 days. Given that alternative treatments, particularly for stage II-IIIA disease, do not offer the same chance of long-term survival, we would suggest that these figures are low. The risks must be viewed in the context of prognosis without an operation and whilst clinicians must understand the factors associated with increased risk, it is not just the clinician's but also the patient's perception of risk which is important. A review of the currently accepted standards for surgical mortality in the context of open discussions with patients may be called for to ensure that all eligible patients are allowed to consider this potentially curative treatment.

The use of early deaths after lung cancer surgery as a measure of performance of individual thoracic surgeons, which may be introduced for revalidation, has raised concerns over risk-averse patient selection by surgeons. It is clearly important that if mortality figures are to be used in this way they are adjusted for the factors which we have shown to be strongly associated with early postoperative death (most importantly age and PS) and ideally fully adjusted using a risk prediction model, so that surgeons are not any less inclined to offer surgery to a patient of borderline fitness.

\section{CONCLUSION}

We were able to use the NLCA data to develop a score which estimates 90-day mortality risk for patients with NSCLC, based on an English population. Whilst this needs assessment in other cohorts, it has potential to increase the accuracy with which we can predict outcomes in lung cancer surgery. In the meantime, it is important that clinicians are aware of the limitations of risk estimates using Thoracoscore and 30-day mortality figures when applied to patients with lung cancer.

Acknowledgements We would like to acknowledge the contributions of the Nottingham University Lung Cancer PhD Steering Group, and the NHS HSCIC who performed the data linkage.

Contributors HP was involved in study design, performed the majority of data processing and analysis, and drafted the article. The original idea was from $\mathrm{RH}$ and $\mathrm{RH}, \mathrm{RS}, \mathrm{DB}$ and LT contributed to design of the study and interpretation of data. AK assisted with data processing. All authors were involved in revising the article for important intellectual content and approved the article before submission.

Competing interests HP is partly funded by the NIHR through the Nottingham Respiratory Research Unit. RH is the British Lung Foundation-GlaxoSmithKline (GSK) professor of respiratory epidemiology and he has received payment for an advisory meeting from GSK on idiopathic pulmonary fibrosis. AK is funded by the British Lung Foundation and he has received a BLF/GSK travel grant for presenting a separate study using the NLCA at the ERS congress in 2012. DB has received a lecture honorarium from Pierre Fabre and payment for an advisory meeting from Roche. He is a coauthor of the British Thoracic Society Guidelines on the radical management of patients with lung cancer and was clinical lead for the National Institute of Health research guidelines on the diagnosis and treatment of lung cancer. RS is the project manager for the National Lung Cancer Audit and is employed by the NHS Health and Social Care information Centre (HSCIC). LT performs data analysis for the NLCA annual reports. The HSCIC provided the study data, but none of the funding bodies played any role in writing the manuscript or the decision to submit it for publication, and they did not influence the objectives or outcome of the study which was designed and conducted at the University of Nottingham.

Ethics approval The Healthcare Quality Improvement Partnership approved the use of the National Lung Cancer Audit for this work. The authors only had access to anonymised data.

Provenance and peer review Not commissioned; externally peer reviewed.

\section{REFERENCES}

1 Riaz SP, Lüchtenborg M, Jack RH, et al. Variation in surgical resection for lung cancer in relation to survival: population-based study in England 2004-2006. Eur J Cancer 2012;48:54-60.

2 Berrisford R, Brunelli A, Rocco G, et al. The European Thoracic Surgery Database Project: modelling the risk of in-hospital death following lung resection. Eur J Cardiothorac Surg 2005;28:306-11.

3 Brunelli A, Pompili C, Berardi R, et al. Performance at preoperative stair-climbing test is associated with prognosis after pulmonary resection in stage I non-small cell lung cancer. Ann Thorac Surg 2012;93:1796-800.

4 Kates M, Perez X, Gribetz J, et al. Validation of a model to predict perioperative mortality from lung cancer resection in the elderly. Am J Respir Crit Care Med 2009;179:390-5.

$5 \operatorname{Lim} \mathrm{E}$, Baldwin $\mathrm{D}$, Beckles $\mathrm{M}$, et al. Guidelines on the radical management of patients with lung cancer. Thorax 2010;65:1-27.

6 Falcoz PE, Conti M, Brouchet $\mathrm{L}$, et al. The thoracic surgery scoring system (Thoracoscore): risk model for in-hospital death in 15,183 patients requiring thoracic surgery. J Thorac Cardiovasc Surg 2007;133:325-32.

7 Bradley A, Marshall A, Abdelaziz M, et al. Thoracoscore fails to predict complications following elective lung resection. Eur Respir J 2012;40:1496-501.

8 Damhuis R, Schutte P. Resection rates and postoperative mortality in 7,899 patients with lung cancer. Eur Respir J 1996;9:7-10.

9 Fountain SW, Armstrong P, Congleton J, et al. Guidelines on the selection of patients with lung cancer for surgery. Thorax 2001;56:89-108.

10 Strand T-E, Rostad H, Damhuis RAM, et al. Risk factors for 30-day mortality after resection of lung cancer and prediction of their magnitude. Thorax 2007:62:991-7.

11 Rich AL, Tata LJ, Stanley RA, et al. Lung cancer in England: information from the National Lung Cancer Audit (LUCADA). Lung Cancer 2011;72:16-22.

12 Townsend P, Phillimore P, Beattie A. Health and deprivation: inequality and the north. London: Croom Helm, 1988.

13 Rich AL, Tata LJ, Free CM, et al. Inequalities in outcomes for non-small cell lung cancer: the influence of clinical characteristics and features of the local lung cancer service. Thorax 2011:66:1078-84.

14 Charlson ME, Pompei $\mathrm{P}$, Ales $\mathrm{KL}$, et al. A new method of classifying prognostic co-morbidity in longitudinal-studies-development and validation. J Chron Dis 1987;40:373-83.

15 NHS Information Centre. National lung cancer audit 2012, report for the audit period 2011. 2012.

16 Audit Commission. Improving data quality in the NHS: annual report on the PbR assurance programme. London: Audit Commission Publishing Team, 2010.

17 Damhuis RAM, Wijnhoven BPL, Plaisier PW, et al. Comparison of 30-day, 90-day and in-hospital postoperative mortality for eight different cancer types. $\mathrm{Br} /$ Surg 2012;99:1149-54.

18 Bryant AS, Rudemiller K, Cerfolio RJ. The 30-versus 90-day operative mortality after pulmonary resection. Ann Thorac Surg 2010;89:1717-23.

19 Cancer Research UK. Lung cancer-UK incidence statistics. 2011.

20 Riaz SP, Linklater KM, Page $R$, et al. Recent trends in resection rates among non-small cell lung cancer patients in England. Thorax 2012;67:811-14. 